\title{
Agroindustrialização de Alimentos nos Assentamentos Rurais do Entorno do Parque Nacional da Serra da Bodoquena e sua Inserção no Mercado Turístico, Bonito/MS
} Agroindustrialization of Victuals in the Rural Establishments surround of the Parque Nacional da Serra da Bodoquena and your Insertion in the Tourist Market, Bonito, MS Agroindustrialisation des Aliments dans les Places Rurals à l'entour du Parc National de la Momtagne de Bodoquena et son Insertion au Marché Touristique Bonito/MS Agroindustrialización de los Alimentos em los Sítios Rurales al entorno del Parque Nacional da Serra da Bodquena y su inserción em el Mercado Turístico, Bonito/MS

\author{
Liliane Lacerda* \\ Lidiamar Barbosa de Albuquerque ${ }^{* *}$ \\ Sinéia Mara Zattoni Milano* \\ Márcia Brambilla*
}

Recebido em 10/11/2006; revisado e aprovado em 20/2/2007; aceito em 22/2/2007.

\begin{abstract}
Resumo: Os projetos de assentamentos rurais possibilitam o acesso a terra, entretanto as famílias assentadas ainda enfrentam dificuldades ao tentar tirar dela o seu sustento. Uma das alternativas para minimizar o problema e viabilizar a sua permanência no campo tem sido a transformação do excedente da produção familiar em produtos agroindustrializados. Assim, o objetivo deste trabalho foi capacitar pequenos produtores rurais dos Assentamentos Guaicurus e Santa Lúcia, localizados no entorno do Parque Nacional da Serra da Bodoquena, Bonito/MS, para a agroindustrialização de frutas e hortaliças, cultivados em bases agroecológicas. Desde sua implantação, foram produzidos 2.682 potes de conservas (2.000 vendidos e 682 consignados). Esta comercialização tem gerado ganhos socioeconômicos para os assentados ao mesmo tempo em que se propõe um modelo produtivo ambientalmente mais adequado, diminuindo a pressão sobre o Parque.
\end{abstract}

Palavras-chave: Assentamentos rurais; agroindustrialização; turismo; Bonito/MS.

Abstract: The projects of rural establishments make possible the access of land; however the families seated still have difficulties when trying to remove your support from the land. One of the alternatives to minimize this problem and to make possible your permanence in the countryside has been the transformation of the surplus of the family production in products agroindustrialized. Inside of this context, the objectives of this work were to qualify small rural producers to do the agroindustrialization of the victuals in the rural establishments Guaicurus and Santa Lúcia, located surround of the Parque Nacional da Serra da Bodoquena, Bonito/MS, and to insert the women in this process of improvement of these products. This works was done in the period between April, 2004 and February, 2005. In that period 2682 pots were produced, of those 2000 they were sold and 682 are consigned at craft stores, restaurants, supermarkets, hotels and gas station. That commercialization has been generating socio-economics won and at the same time generates a productive model more appropriate for the environmental that reducing the pressure on the Park.

Key words: Rural establishments; agroindustrialization; tourism; Bonito/MS.

Résumé: Les projets de places agrairies rendent possible l,access à la tèrre, cependant lês familles placées confrontent difficultés por essayer ôter de la téere leur subsistance. Une des alternatives pour diminuer lê probléme et possibiliter la permanence à la campagne a étéla transformation de l'excedánt de la production familier en produits agroindustrialisés. Ainsi, l’objectif de ce travail a été qualifier modestes producteurs agrairies dans les Places Guaigurus et Santa Lúcia, placés a léntor du Parc National de la Montagne de Bodoquena, Bonito / MS, pour l'agoindustrialisation de fruits e plantes potagéres, cultivés em bases agroecologiques.. Depuis son implantation, 2.682 pots de conserve ( 2.000 et 682 consignés ) ont été produits. Cette comercialisation a engendré profits sociaux et economiques pour les familles placées au même temps que propose um modele productif ambientalllement plus approprié, avec la dininution de la préssion sûr le Parc.

Mots-clé: Places agrairies; agroindustrialisation; tourisme; Bonito/MS.

Resumen: Los proyectos de sítios rurales hacen la posiblidad del accesso à la tierra, todavia las famílias que viven em los sítios aún tienen difculdades em la tentativa de sacar la tierra su subsistência. Uma de las alternativas para minimizar el problema y hacer posible su permanência en el campo tiene sido el cámbio del excedente de la producción familar em produtcos agroindustrializados. Así, el obyectivo de este trabajo fue capacitar pequeños productores rurales em los Sítios Guaicurus y Santa Lúcia, ubicados em el entorno del Parque Nacional da Serra da Bodoquena, Bonito / MS, para la agroindustrialización de frutas y vegetales, cultivados em basies agroecloógicas. Desde su implantación, fueron producidos 2.682 potes de conserva ( 2.000 vendidos y 682 consignados). Esta comercialización tiene gernerado gaños socioeconômicos para los sitiados al mismo tiempo em que se propone um modelo productivo ambientalmente más apropiado, haciendo la diminuición de la présion sobre el Parque. Palabras clave: S’tios rurales; agroindustrialización; turismo; Bonito/MS.

\footnotetext{
*Fundação Neotrópica do Brasil. (lili_bio@yahoo.com.br; pedaserra@fundacaoneotropica.org.br; www.fundacaoneotropica.org.br).

${ }^{* *}$ Professora do Curso de Biologia da Universidade Católica Dom Bosco. (lidiamar98@yahoo.com).
} 


\section{Introdução}

A concentração de terras no Brasil tem suas origens na época do descobrimento. A má distribuição da propriedade da terra é o traço mais marcante, e ao mesmo tempo a principal distorção da estruturação fundiária no Brasil. Para minimizar os efeitos deste modelo surgiram as políticas públicas de reforma agrária. Segundo Sparovek (2003), "reforma agrária é um termo utilizado para descrever distintos processos que procuram dar acesso à posse da terra e aos meios de produção para os trabalhadores rurais que não a possuem ou possuem apenas em pequena quantidade, constituindo-se em um agente transformador e ao mesmo tempo criador de espaços diferenciados". Inseridos nesse processo de transformação, os assentamentos são considerados uma importante alternativa de trabalho e inserção social porque vêm possibilitar o acesso à propriedade da terra para uma população que, principalmente nesses últimos 50 anos de história do Brasil, vem sendo excluída dos benefícios sociais.

Entretanto, "o grande desafio da reforma agrária é ser transformada em instrumento efetivo de desenvolvimento local" (BUAINAIN, 2003). Desamparados por uma política agrária que beneficia o grande produtor, com vistas à exportação em larga escala, os pequenos produtores, sem condições competitivas de mercado, abandonam suas pequenas propriedades e migram para a periferia das grandes cidades, em busca de outro meio de vida. O resultado é o agravamento dos problemas sociais urbanos, aumento da miséria, da fome, da marginalidade, do desemprego e dos problemas ambientais.

\subsection{Agroindustrialização do excedente da} produção familiar como alternativa produtiva para o pequeno produtor rural do município de Bonito/MS

Produzir na pequena propriedade rural tem sido possível, mesmo em condições adversas. Entretanto, um dos grandes entraves para o produtor de pequena escala é a comercialização do excedente de sua produção. Uma das soluções encontradas para minimizar o problema tem sido a verticalização desta produção. "Entende-se por verticalização no campo a transformação do produto in natura em um produto agroindustrializado" (HOMEM DE CARVALHO, 2003). A verticalização agrega valor ao produto quando o transforma, e tira-o da condição de perecível quando permite ao produtor aguardar a hora adequada para comercialização, sem a necessidade de venda imediata após a colheita. Essa proposta de trabalho tem transformado o espaço rural brasileiro ocupado pelos pequenos produtores, em uma nova possibilidade de aumento de sua renda.

O processo crescente de urbanização da sociedade brasileira tem aumentado a demanda por produtos agroindustrializados, e, associado a isso, cresce a valorização de produtos genuinamente regionais, principalmente aqueles comercializados em regiões com apelo turístico.

$\mathrm{Na}$ região de Bonito/MS, os recursos naturais, tanto reais quanto potenciais, funcionam como elementos atrativos para o turismo. Frente a essas e muitas outras peculiaridades do município, a região é considerada como um espaço privilegiado para a comercialização de produtos agroindustrializados. A dificuldade de comercialização encontrada pelos pequenos produtores, que já foi um dos maiores desestímulos à produção agrícola regional, atualmente encontra no comércio turístico local e na Feira do Produtor Rural, recentemente criada no município, uma oportunidade de negócio.

No sentido de oferecer uma alternativa para minimizar os problemas impostos pelo atual modelo econômico, levando em conta o potencial ecoturístico regional e a necessidade de conservação do entorno do Parque Nacional da Serra da Bodoquena, a Fundação Neotrópica do Brasil, uma organização não-governamental ambientalista, idealizou o projeto "Qualificação e Diversificação da Produção de Alimentos pelas Mulheres dos Assentamentos Rurais do Entorno do Parque Nacional da Serra da Bodoquena". Este trabalho de capacitação foi elaborado como complementação das ações de outro projeto desenvolvido pela mesma fundação, o "Projeto Ecodesenvolvimento no Entorno do Parque Nacional da Serra da Bodoquena". 
Dentre as diversas atividades do Projeto Ecodesenvolvimento, um dos componentes é incentivar e apoiar práticas agroflorestais de produção, em bases agroecológicas, nos assentamentos rurais localizados no entorno do Parque. O projeto de capacitação para a agroindustrialização do excedente dessa produção, tem por objetivos fortalecer e complementar esta atividade, fazendo uso do potencial do mercado turístico regional. Desta forma, a ação da Fundação Neotrópica nos assentamentos, pretende dar ao assentado rural e sua família condições de produzir, industrializar e comercializar seus produtos, garantindo-lhes emprego, renda e vida digna, ao mesmo tempo em que diminui a pressão exercida pela ocupação humana sobre a área do Parque Nacional da Serra da Bodoquena.

Dentro deste contexto, o presente trabalho tem por objetivo fazer a agroindustrialização dos alimentos nos assentamentos rurais Guaicurus e Santa Lúcia, situados no entorno do Parque Nacional da Serra da Bodoquena, em Bonito/MS, inserindo as mulheres no beneficiamento desses produtos. Para alcançar esse objetivo geral, o projeto teve como objetivos específicos: (a) Oferecer qualificação de mão-de-obra para a agroindustrialização de frutas e hortaliças em geral; (b) Agregar valor aos produtos dos assentamentos, a partir do cultivo com bases agroecológicas, transformando a produção in natura em produtos agroindustrializados; (c) Contribuir para a conservação do Parque Nacional da Serra da Bodoquena; (d) Fortalecer a "Feira dos Pequenos Produtores", diversificando a oferta e melhorando a apresentação dos produtos comercializados; (e) Contribuir para a inserção dos produtos agroindustrializados no crescente mercado turístico do município de Bonito; (f) Melhorar a qualidade de vida das comunidades envolvidas.

\section{Procedimentos metodológicos}

\subsection{Caracterização da área de abrangência}

Este trabalho foi realizado nos projetos de assentamentos rurais Santa Lúcia e Guaicurus, situados no entorno do Parque Nacional da Serra da Bodoquena, Bonito/MS.

\subsubsection{O Parque Nacional da Serra da Bodoquena}

O Parque Nacional da Serra da Bodoquena foi criado em 21/09/2000. "Sua área possui um imenso patrimônio natural, em boas condições de preservação, abrigando a maior extensão de florestas naturais do estado de Mato Grosso do Sul. O Parque é formado por duas áreas bem próximas uma da outra, somando 76.481 ha. A área Norte, com 27.797 ha, engloba parte da Bacia do Rio Salobra, e a Sul, com 48.684 ha, parte da Bacia do Rio Perdido. Sua área de influência abrange os municípios de Bonito, Bodoquena, Porto Murtinho e Jardim, localizados no sudoeste do Estado, na região Centro-Oeste brasileira" (FUNDAÇÃO NEOTRÓPICA DO BRASIL, 2004).

O Parque é caracterizado por um maciço rochoso elevado com altitudes que variam de 450 a 650 metros onde se encontra um dos últimos remanescentes da floresta estacional semi-decidual. Nas áreas elevadas infiltram as águas pluviais que abastecem os rios que cortam a Serra da Bodoquena. "A manutenção das condições ambientais desta parte da serra se tornou indispensável não apenas do ponto de vista ecológico, mas também social, econômico e político, ainda mais que entre as 87 áreas prioritárias para a conservação da biodiversidade no bioma Cerrado e no Pantanal, a Serra da Bodoquena foi considerada de elevada importância, devido à riqueza de espécies e os endemismos" (FUNDAÇÃO NEOTRÓPICA DO BRASIL, 2004).

\subsubsection{O município de Bonito}

A colonização de Bonito data de meados do século XIX, "quando as primeiras habitações foram edificadas na outrora Fazenda Rincão Bonito. Sua fundação foi oficializada pelo decreto do governador de 14/ 06/1927. Bonito passaria à categoria de município somente em 02/10/1948" (DIAS, 1998). O Município de Bonito ( $21^{\circ} 07^{\prime} 16^{\prime \prime} \mathrm{S}$ e $56^{\circ} 28^{\prime} 55^{\prime \prime} \mathrm{W}$ ) possui uma área total de 4.934 $\mathrm{km}^{2}$, correspondendo a $1,40 \%$ das terras do Estado, faz limite com os municípios de Bodoquena ( $\mathrm{N}$ e NO), Miranda (N), Anastácio (NE), Nioaque (L), Guia Lopes da Laguna (SE), Jardim (S) e Porto Murtinho 
(SO e O). De acordo com o Anuário Estatístico de Mato Grosso do Sul - 1993 - SEPLANMS, o município de Bonito abriga uma população de 17.948 habitantes, dos quais 8.344 residentes na zona urbana e 9.604 na zona rural.

Apesar da longa distância dos grandes centros urbanos do país, Bonito destacase, regionalmente, como uma área promissora dentro do Estado, em função de sua beleza cênica. "Bonito aparece no cenário sul-mato-grossense como uma região de expressão, especialmente pela fama propiciada pelo turismo, além das reservas de recursos minerais, principalmente calcários e mármores, ou pelo desenvolvimento da atividade pecuária na região há muitos anos" (DIAS, 1998).

\subsubsection{Assentamento Guaicurus}

Criado oficialmente em 1986, o assentamento Guaicurus tem 2.722 ha de área e comporta atualmente, 120 famílias e aproximadamente 500 pessoas. $\mathrm{O}$ assentamento está a Sudoeste da porção Norte do parque. Para acessá-lo a partir de Bonito é necessário passar por entre as duas partes que compõem o parque. Suas terras estão localizadas entre a área do Parque e a Terra Indígena Kadiwéu.

A característica do solo é de regiões montanhosas com afloramentos rochosos notáveis. Também tem escassez de água, o que dificulta ainda mais a agricultura. "Apenas $1 \%$ de suas terras é cultivada com agricultura de subsistência e o restante é ocupado com pastagens" (FUNDAÇÃO NEOTRÓPICA DO BRASIL, 2004).

De acordo com Milano (2002), o "assentamento possui duas reservas legais bastante degradadas e segundo informações de alguns moradores, ainda se retira madeira dessas áreas para utilização em algumas propriedades, uma vez que muitas não possuem madeira para o próprio consumo, comprovando a existência do extrativismo irregular".

\subsubsection{Assentamento Santa Lúcia}

Em 1998, o Governo Federal, através do INCRA, "desapropriou 1.026,74 ha de terras da Fazenda Santa Lúcia, no município de Bonito, dando início ao projeto de assentamento de 37 famílias, somando aproximadamente 100 pessoas" (IDATERRA, 2001). Suas divisas estão próximas ao lado leste da porção sul do parque, em sentido a Porto Murtinho pela MS-178.

Os solos, onde hoje está o Santa Lúcia, são aptos à prática agrícola desde que corrigida sua acidez. A pecuária é desenvolvida em menor ou maior grau por todos os assentados, apresentando um potencial para o incremento da bovinocultura de leite e culturas anuais,. Paralelamente à bovinocultura, ocorre, em menor escala, a suinocultura e a criação de galinha caipira. "Para àqueles produtores que seguem as orientações técnicas, a produtividade tem sido satisfatória, tanto da agricultura como da pecuária" (MILANO, 2002).

De acordo com Milano (2002), o "assentamento possui duas áreas de preservação permanente. Uma compreendida em 216,52 ha de várzea, em região de nascentes do Rio da Prata, cujas águas drenam para o Rio Miranda que por sua vez é afluente do Rio Paraguai e outra, uma área de reserva legal, com 205,88 ha de vegetação natural em estágio avançado de regeneração. Esta última tem sido utilizada irregularmente, por alguns moradores, como área de pastagem".

\subsection{Projeto Pé-da-Serra}

O projeto "Qualificação e diversificação da produção de alimentos pelas mulheres dos Assentamentos Guaicurus e Santa Lúcia, localizados no entorno do Parque Nacional da Serra da Bodoquena" conta com o apoio financeiro do Programa de Pequenos Projetos (PPP), Fundo para o Meio Ambiente Mundial (GEF) e Programa das Nações Unidas para o Desenvolvimento (PNUD), aprovado em setembro de 2003, com duração de 18 meses. Os dados apresentados neste trabalho são referentes aos meses de abril de 2004 a fevereiro de 2005.

Considerando o papel fundamental da mulher na transmissão de conhecimentos dentro da família e na comunidade em geral, optou-se por investir na capacitação do gênero feminino, ou seja, das produtoras rurais dos assentamentos Santa Lúcia e 
Guaicurus, valorizando suas capacidades produtivas e inserindo-as diretamente no processo de geração de renda familiar.

Este projeto foi desenvolvimento em 7 etapas:

\subsubsection{Assinatura do termo de adesão}

Em Agosto de 2003, para a elaboração do projeto, foram realizadas visitas técnicas aos assentamentos para conhecer o espaço, a sua realidade socioeconômica e avaliar a sua capacidade produtiva.

Em janeiro de 2004, foram organizadas reuniões nas comunidades para discussão coletiva sobre alternativas de produção que fossem ao mesmo tempo lucrativas e ambientalmente mais adequadas em relação as tradicionais formas de produção até então desenvolvidas na região.

O passo seguinte, após consenso sobre as ações a serem implementadas pelo projeto, os interessados em participar das atividades assinaram um "Termo de Adesão ao Projeto" o qual foi anexado à proposta de trabalho apresentada ao órgão financiador.

\subsubsection{Adequação da estrutura das sedes dos assentamentos para a criação de cozinhas comunitárias.}

Para iniciar o processo de capacitação e industrialização dos produtos, foi necessária a criação de cozinhas comunitárias nos dois assentamentos, obedecendo a normas da Secretária de Saúde/Vigilância Sanitária. Para a criação das cozinhas, foram realizadas reuniões com os presidentes das associações de moradores dos Assentamentos Santa Lúcia e do Guaicurus, além de membros das comunidades, para serem autorizadas obras de reformas para adequações das estruturas das sedes desses assentamentos em cozinhas comunitárias. Para a execução dessas obras, foi estabelecida parceria com a Prefeitura Municipal de Bonito, que cedeu arquiteto e materiais de construção para a sua realização. As obras foram iniciadas em agosto e terminaram em setembro de 2004, em ambos os assentamentos.

\subsubsection{Organização de cursos}

Dando início às atividades do projeto, propriamente ditas, foram planejados cursos de capacitação. Para esta atividade, firmou-se parceria com o Serviço Nacional de Aprendizagem Rural/SENAR que se responsabilizou pela realização da maioria dos cursos planejados. Todo o planejamento foi elaborado para diversificar e qualificar a mão-de-obra das mulheres dos assentamentos rurais para a agroindustrialização do excedente de sua produção. Foram agendados 02 (dois) cursos de processamento de alimentos para o ano de 2004: "Processamento de Frutas e Hortaliças em Conservas Doces e Salgadas e Produção Caseira dos Derivados da Mandioca", ambos realizados respectivamente, em junho e novembro.

\subsubsection{Criação da marca, compra de emba- lagens, elaboração e compra de rótulos e etiquetas e criação do mate- rial de divulgação.}

Uma tarefa importante foi à criação de uma marca que identificasse o projeto e pudesse abrigar todos os produtos. O paço seguinte incluiu a criação de rótulos, etiquetas e material de divulgação. Os rótulos obedeceram às normas básicas da Secretaria Nacional de Vigilância Sanitária, com a impressão de informações sobre o produto e com o carimbo de autorização para a comercialização. A elaboração de etiquetas mereceu uma atenção especial. Elas serviriam para acompanhar cada um dos produtos, como um "Certificado de Origem".

\subsubsection{Organização da produção}

Com a estrutura da cozinha montada e os detalhes das embalagens prontos, deuse início a produção dos doces e conservas. A produção foi iniciada com a normatização do uso das cozinhas comunitárias e de seus utensílios, bem como com a organização da utilização de embalagens, rótulos e etiquetas. Elegeu-se uma coordenadora para cada assenamento. 


\subsubsection{Comercialização}

Para a inserção dos produtos agroindustrializados no mercado de Bonito, foi organizado um lançamento formal na Feira do Produtor, com baile animado por músicos moradores dos assentamentos e palestras sobre o projeto, nos quais compareceram as comunidades dos assentamentos, autoridades locais e a população da cidade em geral.

O projeto também capacitou as mulheres para a venda de seus produtos. Para o cumprimento desta meta, pelo menos uma pessoa da comunidade produtora acompanhou um dos coordenadores da Fundação Neotrópica nas visitas aos estabelecimentos comerciais. No primeiro contato com os revendedores, explicou-se os objetivos do projeto e solicitou-lhes a cooperação e a parceria.

O resultado da venda foi repassado para cada um dos grupos produtores. Antes, porém, fez-se a dedução do valor da embalagem, do rótulo e da etiqueta, inicialmente adquiridos com recursos do projeto, para garantir a sustentabilidade do processo.

\subsubsection{Avaliação dos produtos}

Como forma de se avaliar a aceitação dos produtos no mercado, foram criadas tabelas para o controle de venda e consignação. Dessas tabelas foram retirados dados, tais como: produtos mais vendidos, quantidade total vendida, total de pontos de venda e em qual categoria se inserem (restaurantes, hotéis, pousadas, supermercados, lojas de artesanato, dentre outras).

Periodicamente, visitam-se os estabelecimentos do comércio onde estão expostos os produtos para avaliar se sua aparência continua a mesma, ou seja, se apresentam descoloração ou qualquer outro indicativo de contaminação. Em caso positivo, providencia-se a substituição imediata do mesmo.

\section{Resultados e Discussões}

Através da assinatura do termo de adesão, 17 pessoas do assentamento Santa Lúcia e 36 pessoas do Guaicurus confirmaram sua participação no projeto. Entretanto, como participantes efetivos foram conside- rados os que fizeram os cursos de capacitação e os que produziam frutas e legumes em suas hortas e pomares.

Para cumprir exigências da Vigilância Sanitária e iniciar o processo de capacitação e industrialização, foram implantadas as cozinhas comunitárias, uma em cada assentamento para o processo de beneficiamento, pois a vigilância exige que se tenha um local apropriado, obedecendo as normas básicas de instalação. Essas "cozinhas comunitárias" foram equipadas, com recursos do projeto, com (1) um fogão semi-industrial, (1) um freezer doméstico tamanho médio, panelas de diversos tamanhos e outros equipamentos básicos.

Antes dessa adequação, ocorreram 02 cursos de capacitação em 2004. O primeiro, em julho, de "Conserva de Frutas e Hortaliças" com a participação de 12 mulheres no assentamento Santa Lúcia e 12 no Guaicurus. $\mathrm{O}$ segundo, em novembro, "Produção caseira dos Derivados da Mandioca", com a participação de 15 alunas no Santa Lúcia e 12 no Guaicurus.

A diferenciação e originalidade dos produtos da pequena agroindústria têm sido apontadas como uma importante estratégia para a inserção e ampliação de espaço no mercado. Esta diferenciação, entretanto, não é suficiente. Segundo Araújo (2005) é necessária a promoção de uma nova relação, mais estreita da pequena agroindústria com os consumidores, com base em um "conceito referencial" de qualidade, com uma categorização dos produtos, constituindo e fortalecendo marcas locais dos assentamentos, associadas à sua cultura e à sua realidade".

Essa premissa embasou a escolha da marca "Pé-da-Serra", por ser um indicativo da localização geográfica dos assentamentos, bem como a criação das etiquetas como um "certificado de origem", indicando o produtor, o local de produção, as características básicas do produto, a história e os objetivos do projeto. Assim, os produtos são diferenciados dos demais por representar uma marca regional, além de se tornarem competitivos também pelo seu processo de produção e suas características intrínsecas. De acordo com o Pronaf (2005), "um conjunto de características podem ser incorporadas aos alimentos e, assim, materializar a diferenciação dos pro- 
dutos da pequena agroindústria, numa associação com o local de sua produção e com o saber-fazer dos agricultores, conferindo-lhes sabor peculiar, apreciado por um percentual cada vez maior da população".

Após a etapa de criação da marca, foi elaborado um layout para rótulos, etiquetas e outros materiais de divulgação. Foram confeccionados 15 (quinze) banners medindo $60 \times 90 \mathrm{~cm}$, expostos em diversos pontos de venda e 02 (dois) banners medindo 1,80x1,00 m, que acompanham a exposição do projeto em diversos eventos. Também, foram providenciadas toalhas de mesa e uniformes com a marca Pé-da-Serra. Esse material é utilizado pelas produtoras na Feira do Produtor, local de venda direta dos produtos Pé-da-Serra e em outros eventos de demonstração dos produtos. Para a legalização da comercialização dos produtos, providenciouse a documentação necessária ao cadastramento junto à Secretaria Municipal de Vigilância Sanitária do município, onde se obteve o registro n. 13/04 da inspeção sanitária.
Com a estrutura da cozinha montada e os detalhes das embalagens prontos, a produção dos doces e conservas Pé-da-Serra foi iniciada após a organização da produção por parte da Fundação Neotrópica do Brasil. Para tal, foram realizadas reuniões com as mulheres interessadas em participar do projeto, nas quais se decidiram normas básicas para utilização da cozinha. Também foi decidido a escolha de uma coordenadora geral da cozinha para cada assentamento, a qual foi incumbida de controlar os dias e a quantidade de produção, estoque de potes (embalagens), organização e limpeza das cozinhas, rotulagem e etiquetagem dos produtos, dentre outras atividades.

As mulheres também decidiram se organizar em grupos de produção. Em ambos os assentamentos, Santa Lúcia e Guaicurus, foram montados 03 (três) grupos, totalizando 10 mulheres em cada um. Dessa forma, em outubro, elas começaram a produção dos doces e conservas de legumes existentes nos seus lotes (Tabela 1).

Tabela 1 - Relação dos produtos Pé-da-Serra produzidos nos assentamentos Santa Lúcia e Guaicurus, Bonito, MS.

\begin{tabular}{|c|c|c|c|c|c|}
\hline Prod utos Pé-d a-Serra & \multicolumn{5}{|c|}{ (b) Locasis de comercialização } \\
\hline (c) Doces & Bonito & Jardim & Nioag ue & Miranda & Campo Grande \\
\hline Mamão ralado & $\mathrm{X}$ & $\mathrm{X}$ & $\mathrm{X}$ & & $\mathrm{X}$ \\
\hline Mamão em pedaço & $\mathrm{x}$ & $\mathrm{x}$ & $\mathrm{x}$ & $\mathrm{x}$ & $\mathrm{x}$ \\
\hline Mamão com abóbora & $\mathrm{x}$ & & & & \\
\hline Abóbor a em pasta & $\mathrm{x}$ & $\mathrm{x}$ & $\mathrm{x}$ & & $\mathrm{x}$ \\
\hline Abóbora em pedaço & $\mathrm{x}$ & $\mathrm{x}$ & $\mathrm{x}$ & $\mathrm{x}$ & $\mathrm{x}$ \\
\hline Laranja & $\mathrm{x}$ & $\mathrm{x}$ & $\mathrm{x}$ & $\mathrm{x}$ & \\
\hline Laranja com abóbora & $\mathrm{x}$ & & & & \\
\hline Goiaba & $\mathrm{x}$ & $\mathrm{x}$ & $\mathrm{x}$ & $\mathrm{x}$ & \\
\hline Leite & $\mathrm{x}$ & $\mathrm{x}$ & $\mathrm{x}$ & $\mathrm{x}$ & $\mathrm{x}$ \\
\hline Manga & $\mathrm{x}$ & $\mathrm{x}$ & & $\mathrm{x}$ & \\
\hline Carambola & $\mathrm{x}$ & $\mathrm{x}$ & $\mathrm{x}$ & $\mathrm{x}$ & $\mathrm{x}$ \\
\hline P êssego & $\mathrm{x}$ & & & & \\
\hline \multicolumn{6}{|l|}{ (d) Geléias } \\
\hline Acerola & $\mathrm{X}$ & $\mathrm{X}$ & $\mathrm{X}$ & $\mathrm{X}$ & $\mathrm{X}$ \\
\hline Goiaba & $\mathrm{x}$ & & $\mathrm{x}$ & $\mathrm{x}$ & $\mathrm{x}$ \\
\hline Laranja & $\mathrm{x}$ & $\mathrm{x}$ & $\mathrm{x}$ & $\mathrm{x}$ & $\mathrm{x}$ \\
\hline Limão & $\mathrm{x}$ & $\mathrm{x}$ & $\mathrm{x}$ & $\mathrm{x}$ & $\mathrm{x}$ \\
\hline Tamarindo & $\mathrm{x}$ & & & & \\
\hline Jabuticaba & $\mathrm{x}$ & & & & \\
\hline Abóbora & $\mathrm{x}$ & $\mathrm{x}$ & $\mathrm{x}$ & & $\mathrm{x}$ \\
\hline \multicolumn{6}{|l|}{ (e) Sucos } \\
\hline Manga & $\mathrm{X}$ & & $\mathrm{X}$ & $\mathrm{X}$ & $\mathrm{X}$ \\
\hline Maracujá & $\mathrm{x}$ & $\mathrm{x}$ & $\mathrm{x}$ & & $\mathrm{x}$ \\
\hline \multicolumn{6}{|l|}{ (f) Conservas } \\
\hline Pimenta & $\bar{x}$ & $\bar{X}$ & $\bar{x}$ & $\bar{x}$ & $\mathrm{X}$ \\
\hline Legumes & $\mathrm{x}$ & $\mathrm{x}$ & $\mathrm{x}$ & $\mathrm{x}$ & $\mathrm{x}$ \\
\hline
\end{tabular}


Para a inserção dos produtos Pé-daSerra no mercado de Bonito, foi realizado um lançamento na Feira do Produtor, com um baile e palestra sobre o projeto, para as quais foram convidadas todas as comunidades dos assentamentos e a população em geral da cidade. No período de novembro de 2004 a março de 2005, foram produzidos 2682 potes (Tabela 2). Com o sucesso do lançamento, a inserção dos produtos nas lojas de Bonito foi facilitada, em função da apresentação do produto em embalagens atraentes e do carimbo do serviço de inspeção sanitária.

Tabela 2 - Total de produção, venda, consignação e estoque dos produtos Pé-da-Serra, produzidos nos assentamentos Santa Lúcia e Guaicurus, Bonito, MS.

\begin{tabular}{cc|c|c|c|c}
\hline (g) Assentamento & Produção & Vend a & Consignação & Estoq ue \\
\hline $\begin{array}{c}\text { Santa Licia } \\
\text { Guatcurus }\end{array}$ & 1975 & 1094 & 348 & 533 \\
& (i) Total & 2682 & 1545 & 591 & 546 \\
\hline
\end{tabular}

“Com a expansão da produção, cresce naturalmente a necessidade de ampliar os pontos de venda que viabilizem a comercialização dos produtos" (Homem de Carvalho, 2003). E, por Bonito ser uma cidade turística e apresentar um grande potencial de mercado a tudo que se relaciona a produtos rurais, tem-se atualmente 18 pon- tos de venda das compotas e conservas Péda-Serra no município (Figura 1). O sucesso que os produtos Pé-da-Serra vêm alcançando é em função de serem genuinamente regionais, associado a isso tem o fato de serem produzidos em uma cidade turística e, não possuírem adição de produtos químicos.

Figura 1 - Pontos de venda dos produtos Pé-da-Serra, produzidos nos assentamentos Santa Lúcia e Guaicurus, Bonito, MS.
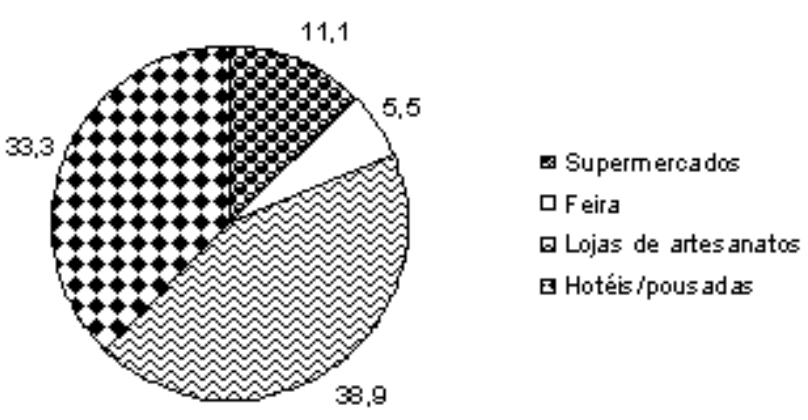

Além desses fatores, percebe-se em Bonito uma transformação no próprio comportamento populacional, após a abertura do seu espaço para o turismo. De acordo com Dias (1998), "a necessidade de uma adequação a um setor econômico ligado, diretamente, à satisfação de grupos sociais destinados ao lazer, implica, necessariamente, na ado- ção de conceitos e comportamentos refinados pela sociedade local". Percebeu-se isso através da grande aceitação dos produtos Pé-da-Serra pela população local e turista, o que tem propiciado a inserção dos produtos em outros municípios como Campo Grande, com 4 pontos de venda, Jardim, 1, Miranda, 1 e Nioaque, 1 (Figura 2 e Tabela 1). 
Figura 2 - Pontos de venda dos produtos Pé-da-Serra nos municípios de Campo Grande, Jardim, Miranda e Nioaque, MS.

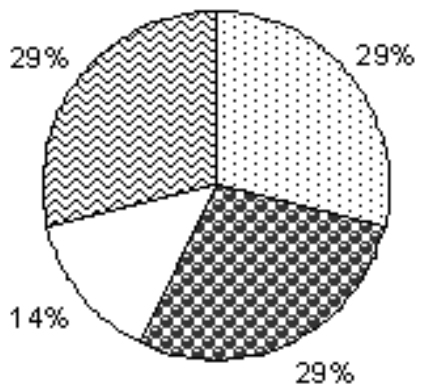

De novembro de 2004 até fevereiro de 2005, foram vendidos 1545 potes (Tabela 2) e 591 estão atualmente consignados nas lojas de artesanato, restaurantes, supermercados, hotéis/ pousadas e postos de combustível dos municípios citados acima.

Entretanto, por ser uma atividade complexa, não se pode conceber que a agroindustrialização seja a solução única e imediatamente aplicável para a geração de renda e agregação de valor à produção dos assentados. Apesar do impacto econômico se dar de uma forma significativamente positiva, com a dinamização da economia local, as produtoras do projeto queriam que o retorno financeiro fosse mais rápido. Mas, o faturamento líquido por cada assentamento foi em média de $\mathrm{R} \$ 206,00$ por semana, desta forma a movimentação financeira foi em torno de $\mathrm{R} \$ 824,00$ por mês. Tendo em vista que, muitas mulheres não tinham renda mensal ou quando possuíam era resultado da venda de produtos in natura na Feira do Produtor, esse dinheiro veio complementar a renda familiar. Segundo Homem de Carvalho (2003), "é favorecido um modelo de desenvolvimento local sustentável, onde o estímulo para a melhoria da economia está condicionado ao surgimento de iniciativas que favoreçam o aumento, a permanência e a (re)aplicação da renda no próprio município e arredores. Uma conseqüência imediata é o surgimento e/ou fortalecimento do comércio local, estimulado pelo aumento do consumo de alimentos, de vestuário, calçados, de eletrodomésticos, de equipamentos, ferramentas e materiais de construção, e outros insumos usados na produção e industrialização agropecuária".

\author{
QPostos de combustivel \\ DSupermercados \\ 口Feiras \\ QLojas de artesanatos
}

Com a aceitação e comercialização cada vez maior dos produtos, houve um avanço no que se refere a ganhos sócio-econômicos. Mesmo nos casos em que as produtoras se mostraram insatisfeitas com a renda, foi possível identificar lucros, que foi reinvestido no negócio. Isto levou ao entendimento de que a agroindústria, no caso estudado, além de representar fonte de renda complementar tem servido como instrumento de mudança da postura do trabalhador rural diante do mundo dos negócios. Observa-se que algumas mulheres, começam a fazer o controle das despesas e receitas, demonstrando maior discernimento sobre os mecanismos de mercado e capacidade de gestão de seus negócios. Está havendo, sem dúvidas, a assimilação de elementos que até então não faziam parte de sua realidade.

A verticalização dos produtos agrícolas em pequena escala, no próprio ambiente rural apresentou-se como a melhor alternativa para a capitalização dos assentamentos Santa Lúcia e Guaicurus, precisamente por permitir a ocupação da mão-de-obra familiar na atividade produtiva e a agregação de valor aos produtos. Por outro lado, deu uma nova motivação para as comunidades, que não tinham muitas opções de geração de renda. Segundo Brasil (2005), “a implantação de agroindústrias é uma das alternativas econômicas para a permanência dos agricultores familiares no meio rural. Oportuniza a inclusão social especialmente de segmentos menos privilegiados como, por exemplo, as mulheres, os idosos e os jovens. Para essas pessoas pode representar o (re)início da construção de cidadania, bem como uma oportunidade de resgate de valores sociais e culturais. É uma 
importante alternativa para promover a participação dos assentamentos no processo produtivo e no mercado".

Pode-se citar, também, como fator positivo deste trabalho, o fato de ter tirado da clandestinidade algumas produtoras caseiras que produziam sem inspeção sanitária, oferecendo-lhes oportunidades e condições para produzir com qualidade e de acordo com as exigências legais do mercado. Essas mulheres começaram a ofertar e consumir alimentos de qualidade, livres de aditivos químicos e supriram suas dificuldades em manter estoque mínimo de matéria-prima, para garantir a freqüência necessária de abastecimento do mercado.

\section{Considerações Finais}

O sucesso que os produtos Pé-da-Serra vêm alcançando pode ser creditado a diversos fatores, entre os quais o fato de ser genuinamente regional, de boa qualidade e apresentação, produzidos artesanalmente com matéria prima cultivada em bases agroecológica e sem adição de produtos artificiais. Todos esses fatores, agregados ao potencial de um mercado turístico em expansão, fazem dos produtos Pé-da-Serra uma alternativa viável e criativa de desenvolvimento local. Segundo Homem de Carvalho (2003), "é favorecido um modelo de desenvolvimento local sustentável, onde o estímulo para a melhoria da economia está condicionado ao surgimento de iniciativas que favoreçam o aumento, a permanência e a (re)aplicação da renda no próprio município e arredores. Uma conseqüência imediata é o surgimento e/ou fortalecimento do comércio local, estimulado pelo aumento do consumo de alimentos, de vestuário, calçados, de eletrodomésticos, de equipamentos, ferramentas e materiais de construção, e outros insumos usados na produção e industrialização agropecuária".

Com este trabalho concluiu-se que com determinação e investimento, por parte da
Fundação Neotrópica do Brasil, e força de vontade, por parte dos assentados, pôde-se fazer a inclusão sócio-econômica dessas comunidades através de trabalho digno e promissor. Aliado a este fato, tem-se o ganho ambiental com a diminuição da pressão extrativista sobre o Parque Nacional da Serra da Bodoquena.

\section{Referências}

ARAÚJO, M. L. C. Luta pela terra e modernização da agricultura. Disponível em: <www.fundaj.gov.br/ docs/text/araujo.doc>. Acesso em: 20 jan. 2005.

BRASIL. Programa de Turismo Rural na Agricultura Familiar. Ministério do Desenvolvimento Agrário. Disponível em: <www.pronaf.gov.br/turismo/ programadeturismo rural.pdf $>$. Acesso em: 15 mar. 2005.

BUAINAIN, A. M., Pires, D. Reflexões sobre reforma agrária e questão social no Brasil. Disponível em: <www.ucg.br/ jur/plaestras_pdf/AntonioBuainain.pdf $>$. Acesso em: 15/02/2003.

DIAS, J. As potencialidades paisagísticas de uma região cárstica: o exemplo de Bonito, MS. Dissertação de Mestrado. Presidente Prudente, 1998, 183 p.

Fundação Neotrópica do Brasil, Projeto Ecodesenvolvimento no Entorno do Parque Nacional da Serra da Bodoquena, 2004.

HEREDIA, B. Medeiros, L. Palmeira, M. Cintrão, R. Leite, S. P. Assentamentos rurais e perspectivas da reforma agrária no Brasil. Disponível em: <http:// www.mst.org.br/informativos/minforma / estudo_ufrrj.rtf>. Acesso em: 16 fev. 2005.

HOMEM DE CARVALHO, J. L. Prove - Programa de Verticalização da Pequena Produção Familiar. Brasília. Programa de Gestão Urbana/UN HABITAT, 2. ed, 2003.

IDATERRA - Instituto de Desenvolvimento Agrário e Extensão Rural de Mato Grosso do Sul - Plano de Desenvolvimento Sustentável Projeto de Assentamento Santa Lúcia, Bonito/MS, 2001.

Milano, S. M. Z. Diagnóstico Socioeconômico do entorno do Parque Nacional da Serra da Bodoquena, 2002.

PRONAF - Programa Nacional de Fortalecimento da Agricultura Familiar. O que é agricultura familiar. Disponível em: <http:/ / www.pronaf.gov.br>. Acesso em 08 mar. 2005.

SPAROVEK, G. A qualidade dos assentamentos da reforma agrária brasileira. São Paulo: Páginas \& Letras Editora e Gráfica, 2003. 